\title{
The Frequency of Vaginal Intercourse During Pregnancy: A Systematic and Meta-Analysis Study
}

\author{
Maryam Hasani $^{1}{ }^{\circledR}$, Afsaneh Keramat $^{2 *}$, Raziyeh Maasoumi ${ }^{3,4}$, Maryam Farjamfar $^{5}$, Masud Yunesian $^{6,7}$, \\ Bahare Afshar ${ }^{8}$
}

\begin{abstract}
Objectives: Sexual life may change during pregnancy. Due to negative attitudes toward having sex, unpleasant feeling, and fear of several issues, women might avoid vaginal intercourse during pregnancy. Therefore, the present systematic review aimed to investigate the frequency of vaginal intercourse in pregnancy.

Materials and Methods: Comprehensive literature review was conducted to find the relevant articles published (from December 1990 to April 2018) on the issue including observational studies (e.g., cross-sectional and cohort studies) that certainly determined the mean frequency of vaginal sex throughout pregnancy. In this regard, online international databases such as ISI, PubMed, Scopus, Cochrane, and Google Scholar were independently explored and checked by two authors. Duplicate articles were removed by the EndNote X7 Reference Manager. The results were analyzed using RevMan 5.3 software. The $P<0.05$ was considered significant. Results: Totally, after excluding the duplicate and irrelevant articles based on having the mean frequency of vaginal intercourse during pregnancy, 13 articles were obtained. The range of vaginal intercourse frequency varied from 6.01 to 21 times every month pre-pregnancy, 3.67-9.87 times monthly in the first trimester, 2.78-7.21 times monthly in the second trimester, and 1.35-5.9 times monthly in the third trimester. Five out of the 13 selected articles reporting the mean and standard deviation were entered the current meta-analysis. The frequency of vaginal intercourse was obtained 7.75 (7.13-8.38) times monthly prior to pregnancy, 4.16 (3.86-4.46) times in the first trimester, 6.37 (5.60-7.14) times monthly in the second trimester, and $1.81(1.49-2.13)$ times monthly in the third trimester.

Conclusions: Generally, the frequency of vaginal intercourse decreased in the first trimester while increasing in the second trimester. However, a sharp decline was observed between the second and third trimesters of pregnancy.

Keywords: Frequency, Pregnancy, Trimester, Vaginal intercourse
\end{abstract}

\section{Introduction}

Sexual activity has a profound impact on marital relationships (1) and it affects couples' relationship even in pregnancy (2). In addition, pregnancy has some effects on sexual life (3). It is a remarkable period in a woman's life characterized by significant psychological, physical, physiological, and social changes which can interfere with her well-being (4). It seems that the hormonal, physical, and psychological alterations during pregnancy affect women' tendency toward involving in sexual activity which is subsequently impacted by these changes (5). In this transient stage of life, women may experience an increase of doubts and uncertainties, which can affect their sexual desire to the point that all the sexual activities stop (6). Further, negative attitudes toward having sex in pregnancy influence sexual activity (7). Numerous factors such as fatigue, nausea, vomiting, and sensitive breasts in the first trimester, and physical awkward in late pregnancy due to an increase in abdominal size impose restrictions on sexual activity (8). Therefore, female sexual function is negatively affected by pregnancy due to physical and emotional changes (9). During pregnancy, some women may experience pelvic congestion following the orgasm, which may be disagreeable or even painful. Furthermore, more time (30-60 minutes) is required for the congestion to diminish. It lasts 5-10 minutes to decrease when the woman is not pregnant (6). Considering these profound alternations occurring throughout the pregnancy, the presence of these changes in sexual behaviors is expected during this time as well (7). Some women avoid vaginal intercourse simply since it is uncomfortable or unpleasant during this period. Furthermore, they have some fears about the health of baby including malformation, abnormality, or premature delivery (6).

Although alterations in sexual activity are not inherently a problem (10), pregnant women might be particularly 
susceptible to prolonged sexual changes. These protracted alternations may be detrimental for the couples' sexual life (7) and have a special significance since sexual dysfunctions can arise during pregnancy (9). Long interruption in sexual activity may have negative impacts on intimate relationships since the sexual frequency and sexual satisfaction are closely associated with each other (10). Several studies demonstrated a progressive decline in sexual activity as the pregnancy advanced $(11,12)$ while some other studies reported the same frequency of sexual intercourse in the second trimester compared to the first one (13). Still, other studies came up with contradictory results in this respect $(5,14)$. Therefore, the authors recognized the necessity of a meta-analysis in order to determine the frequency of vaginal intercourse changes.

A number of systematic reviews focused on sexual functions $(15,16)$. Sexual function in women refers to the ability to achieve sexual states as arousal, lubrication, orgasm, and satisfaction $(17,18)$ which are not relevant to the purpose of the present study. A systematic review was conducted on sexual behaviors in pregnancy and post-partum in 2015 and published in the literature. Although its method had some differences such as not focusing on mean frequency of vaginal penetrative sex in pregnancy and not conducting a meta-analysis, the study provided helpful information regarding changes in sexual behaviors during pregnancy (7). Accordingly, since few studies have explored the frequency of vaginal intercourse changes, the authors felt the need to assess the trend of sexual intercourse frequency during pregnancy to find the necessity of intervention during routine care of pregnancy. Thus, a systematic review was implemented to determine the frequency of vaginal intercourse in pregnancy.

\section{Materials and Methods}

Studies which assessed sexual activity in pregnancy were reviewed and the obtained information was used in either data collection or finding section of the current review study. Moreover, studies in which vaginal intercourse was pointed out using the inclusion criteria (that certainly determined mean frequency of vaginal penetrative sex) were included in the review. Additionally, published quantitative studies (from December 1990 to April 2018) including observational studies like cross-sectional and cohort studies were investigated by searching the online international databases such as the Institute for Scientific Information (ISI), PubMed, Scopus, Cochrane, and Google Scholar and the available data were collected. Finally, the studies reporting mean \pm standard deviation (SD) frequency of vaginal intercourse were used for metaanalysis.

The following keywords were combined and used for the purpose of the study: (I) sex, sexuality, sexual function, sexual dysfunction, sexual behavior, sexual activity, sexual practices, sexual preferences, coital frequency, sexual intercourse, intercourse behavior, sexual relationships, vaginal intercourse, coital experience, coital activity, sexual history, marital relation, sexual needs, sex life, and sexual life, (II) pregnant, pregnancy, gestation, expectancy, conception, expectant mother, and trimesters, and (II) frequency, changes, prevalence, number of times, increase, decrease, decline, modify, reduce, reduction, less, more, variation, mutation, ratio, and how often in title and abstract.

In addition, operators such as quotation marks, asterisk $\left.{ }^{*}\right)$, AND, and OR along with NOT as an operator with some keywords such as HIV, virus, contraception were used in the title without any language limitation. The previously mentioned databases were searched for the relevant published articles by 2 authors independently. Duplicates articles were excluded from the review using the EndNote X7 Reference Manager (produced by Thomson Reuters).

Generally, 349 records were identified through searching the databases and other sources. Then, the related section of each selected article was scrutinized. The articles were entered into the EndNote software and after removing the duplicates, 228 references remained. The titles and abstract sections of the articles were checked and thus 184 studies were excluded because of using incompatible methods (e.g., clinical trial, guideline, qualitative study, review, and the like) and not being relevant to our purpose. Therefore, 44 articles were available. The full texts of these studies were obtained. The references of all the included studies were checked in order to find additional articles. The remaining articles were assessed to determine if the study was relevant to our review or not. Eventually, several published reviews $(7,15,16,19)$ were studied to identify any other citations to ensure that the current review was considerably contributing in terms of new perspectives.

The above-mentioned studies were excluded from the current review due to some reasons provided below:

1. Describing the sexual behaviors of a number of pregnant women, which contributed to vaginal and cervical infections (20)

2. Reporting the sexual activity in women with diabetes (21) which was not in accordance with the aims of the present review research

3. Focusing on sexual activity in women with twin pregnancy (22)

4. Investigating the range of sexual activity frequency (e.g., 1-2 times per week or 3-4 times per week, and the like) $(2,3,9,12,23-35)$

5. Focusing on the changes in sexual activity such as increase, decrease, or unchanged (8,36-41) while not reporting the mean frequency of vaginal sex

6. Using the Likert score to obtain the frequency of sexual intercourse, for example, the frequency of sexual intercourse was given score 1,2 , or 3 if it was reported "rarely", "not often", "once per month", or the like $(42,43)$.

7. Highlighting the average of the score for sexual intercourse/activity using FSFI questionnaire (44).

8. Being conducted in the cohort and nesting a casecontrol design (45). Case-control studies are not representative of the community because the 
proportion of the cases to the controls is not based on the real prevalence.

Data Collection and Analysis

Full texts of the remained studies were screened to decide on which studies matched the inclusion criteria. Two authors ( $\mathrm{MH}$ and $\mathrm{BA}$ ) reviewed the full texts of the eligible studies. The necessary data were extracted and entered into an electronic datasheet. Disagreements were settled through discussion among the authors until consensus was obtained. A total of 12 items of STROBE (STrengthening the reporting of OBservational studies in Epidemiology) checklist were used to assess the risk of bias in the included studies (46). Studies with a maximum of 2 unclear bias were regarded as a low-risk bias, otherwise, they were recognized as a high-risk group.

The obtained data were analyzed using the RevMan 5.3 software (Review Manager Copenhagen: The Nordic Cochrane Centre). Further, statistical heterogeneity was explored using chi-square test at the 5\% significance level $(P<0.05)$. Heterogeneity in meta-analysis refers to the variation in study outcomes across the studies. An alternative approach, namely, 'random effects', allows the study outcomes to vary in a normal distribution between the studies (47). Furthermore, the inconsistency across the results of the studies and the between-study variance was estimated employing $\mathrm{I}^{2}$ and tau-squared $\left(\mathrm{Tau}^{2}\right)$ statistics, respectively.

\section{Results}

The mean frequency of vaginal intercourse during pregnancy was reviewed in 13 articles. Moreover, it was compared before and during the pregnancy in most cases. However, in one study the mean frequency of vaginal intercourse was reported only during the second trimester of pregnancy without being compared to that of the prepregnancy (48). Meanwhile, the author's purpose of the sexual activity was mostly vaginal intercourse.

The included studies were conducted in various countries including the United States (3 studies), Turkey (3 studies), Nigeria (3 studies), Iran (1 study), Australia (1 study), Brazil (1 study), and Pakistan (1 study).

Most studies were performed on pregnant women. For instance, one research reported the frequency of vaginal intercourse in men whose wives were pregnant. Additionally, another article addressed the sexual intercourse in men during their wives' pregnancy exclusively. The mean frequency of vaginal intercourse was reported per week or month while in one study it was investigated in the past 2 weeks.

The sample size in these studies varied from 12 to 451 pregnant women. As regards the frequency of sexual intercourse before the pregnancy, it ranged from 6.01 to 21 times monthly. In the first trimester, vaginal intercourse frequency was reported from 3.67 to 9.87 times per month. However, in the second trimester, it ranged from 2.78 to 7.21 times per month. In addition, the mean frequency of vaginal intercourse in the third trimester varied from 1.35 to 5.9 times per month (Table 1).

PRISMA flowchart (Figure 1) was created for each step of the literature search (49).

Out of the 13 articles having the inclusion criteria for



Figure 1. PRISMA Flow CHart. 
Table 1. Frequency Of Vaginal Intercourse (Mean/Weekly/Monthly)

\begin{tabular}{|c|c|c|c|c|}
\hline Author (Year)/Country & Type of Study & Time & $\mathbf{N}$ & $\begin{array}{c}\text { Sexual Exposure } \\
\text { Mean } \pm \text { SD }\end{array}$ \\
\hline \multirow{4}{*}{ Ahmed (2014)/ Egypt } & \multirow{4}{*}{ Prospective cohort study } & Pre-pregnancy & 451 & $7.8 \pm 2.2 /$ monthly \\
\hline & & Trimester1 & 451 & $4.3 \pm 1.2 /$ monthly \\
\hline & & Trimester2 & 451 & $6.4 \pm 2.5 /$ monthly \\
\hline & & Trimester3 & 451 & $1.8 \pm 0.3 /$ monthly \\
\hline \multirow{4}{*}{ Bello (2011)/ Nigeria } & \multirow{4}{*}{ Cross-sectional study } & Pre-pregnancy & 375 & $1.8 / w \approx 7.38 /$ monthly \\
\hline & & Trimester1 & 375 & $1.2 / w \approx 4.92 /$ monthly \\
\hline & & Trimester2 & 375 & $1.4 / w \approx 5.74 /$ monthly \\
\hline & & Trimester3 & 375 & $1.35 / w \approx 5.35 /$ monthly \\
\hline Sacomori (2010)/ Brazil & Descriptive study & Pregnancy & 156 & $5.45 /$ monthly \\
\hline \multirow{4}{*}{ Aslan (2005)/ Turkey } & \multirow{4}{*}{ Prospective cohort study } & Pre-pregnancy & 40 & $8.6 \pm 3 /$ monthly \\
\hline & & Trimester1 & 37 & $6.9 \pm 2.5 /$ monthly \\
\hline & & Trimester2 & 36 & $5.4 \pm 2.6 /$ monthly \\
\hline & & Trimester3 & 34 & $2.5 \pm 1.4 /$ monthly \\
\hline \multirow{4}{*}{ Heidari (2005)/ Iran } & \multirow{4}{*}{$\begin{array}{l}\text { Cross-sectional } \\
\text { descriptive study }\end{array}$} & Pre-pregnancy & 316 & $6.01 \pm 5.17 /$ monthly \\
\hline & & Trimester1 & 316 & $3.97 \pm 4.29 /$ monthly \\
\hline & & Trimester2 & 316 & $2.98 \pm 3.53 /$ monthly \\
\hline & & Trimester3 & 316 & $1.65 \pm 3.13 /$ monthly \\
\hline \multirow{4}{*}{ Bayrami (2005) / Iran } & \multirow{4}{*}{$\begin{array}{l}\text { Cross-sectional } \\
\text { descriptive study }\end{array}$} & Pre-pregnancy & 350 & $7.09 \pm 5.37 /$ monthly \\
\hline & & Trimester1 & 80 & $3.67 \pm 4.39 /$ monthly \\
\hline & & Trimester2 & 150 & $2.78 \pm 3.63 /$ monthly \\
\hline & & Trimester3 & 120 & $1.35 \pm 2.53 /$ monthly \\
\hline \multirow{2}{*}{ Eryılmaz (2004)/ Turkey } & \multirow{2}{*}{$\begin{array}{l}\text { Cross-sectional } \\
\text { descriptive study }\end{array}$} & Pre-pregnancy & 238 & $2.02 \pm 0.7 /$ week $\approx 4.64 /$ monthly \\
\hline & & Pregnancy & 238 & $1.51 \pm 0.6 /$ week $\approx 3.45 /$ monthly \\
\hline \multirow{2}{*}{ Onah (2002)/ Nigeria (Men) } & \multirow{2}{*}{ Descriptive study } & Pre-pregnancy & 279 & $3.2 / w \approx 13.12 /$ monthly \\
\hline & & Pregnancy & 279 & $1.8 / w \approx 7.38 /$ monthly \\
\hline \multirow{2}{*}{ Naim (2000)/ Pakistan } & \multirow{2}{*}{ Descriptive study } & Pre-pregnancy & 150 & $3.5 / w \approx 14.35 /$ monthly \\
\hline & & Pregnancy & 149 & $1.6 / w \approx 6.56 /$ monthly \\
\hline \multirow{4}{*}{ Oruc (1999)/ Turkey } & \multirow{4}{*}{ Descriptive study } & Pre-pregnancy & 158 & $12.4 \pm 5.9 /$ monthly \\
\hline & & Trimester1 & 158 & $8.09 \pm 4.30 /$ monthly \\
\hline & & Trimester2 & 158 & $7.21 \pm 4.61 /$ monthly \\
\hline & & Trimester3 & 158 & $5.29 \pm 3.82 /$ monthly \\
\hline Hyde (1998)/ USA/Women & \multirow{2}{*}{ Descriptive study } & Trimester2 & 570 & $4.97 /$ monthly \\
\hline Hyde (1998) )/ USA /Men & & Trimester2 & 550 & 4.12/monthly \\
\hline \multirow{2}{*}{ Adinma (1995)/ Nigeria } & \multirow{2}{*}{ Descriptive study } & Pre-pregnancy & 440 & $2.3 / w \approx 9.43 /$ monthly \\
\hline & & Pregnancy & 440 & $1.5 / w \approx 6.15 /$ monthly \\
\hline \multirow{4}{*}{ Barclay (1994)/ Australia } & \multirow{4}{*}{ Prospective design } & Pre-pregnancy & 25 & $10 / 2 w \approx 21 /$ monthly \\
\hline & & Trimester1 & 25 & $4.7 / 2 w \approx 9.87 /$ monthly \\
\hline & & Trimester2 & 16 & $3 / 2 w \approx 6.3 /$ monthly \\
\hline & & Trimester3 & 12 & $2.8 / 2 w \approx 5.9 /$ monthly \\
\hline
\end{tabular}

the systematic review, five of them reported the mean frequency and SD and included meta-analysis $(5,11,53-$ 55). These studies were conducted in Turkey (2 studies), Iran (2 studies), and Egypt (1 study). In this regard, considerable heterogeneity existed in the above studies so that the chi-square test result for heterogeneity was extremely significant. Nonetheless, homogeneity was not achieved except for the first trimester.

Vaginal Intercourse Frequency Pre-pregnancy

The 'random effects' model and sensitivity analysis were used to decrease the heterogeneity. The vaginal intercourse 
frequency was 7.75 (7.11-8.38) times before the pregnancy per month including a sample of 841 women (Figures 2 and 3 ).

Vaginal Intercourse Frequency in the First Trimester Using the data of these 5 studies, the frequency of vaginal intercourse in the first trimester was obtained 4.16 (3.864.46) times monthly including 847 women (Figure 3). The random effects model and sensitivity analysis were employed to reduce the heterogeneity.

Vaginal Intercourse Frequency in the Second Trimester To decrease the heterogeneity, the random effects model and sensitivity analysis were used and the frequency of sexual intercourse for a sample of 645 pregnant women was reported $6.37(5.60-7.14)$ times per month in the second trimester (Figure 4).

Vaginal Intercourse Frequency in the Third Trimester The random effects model and sensitivity analysis were applied in order to reduce the heterogeneity. A number of 921 women were examined and the frequency of sexual intercourse was found to be 1.81 (1.49-2.13) times monthly in the third trimester (Figure 5).

Based on the meta-analysis, the mean of vaginal intercourse frequency decreased during the first trimester of pregnancy while it increased in the second trimester. However, the mean of vaginal intercourse frequency reduced for the second time in the third trimester (Figure 6).

\section{Discussion}

Several studies reported changes in sexual activity during pregnancy including those of vaginal intercourse frequency in different trimesters of pregnancy compared to the changes occurred pre-pregnancy.

Based on the results of our literature review, a reduction in intercourse frequency was observed from prepregnancy to the first trimester. It seems that some factors such as fatigue, nausea and vomiting, painful sexual intercourse, changes in body image, and fear of abortion led to a decrease in the frequency of vaginal intercourse in the first trimester of pregnancy.

The results of some studies indicated that $30-90 \%$ of

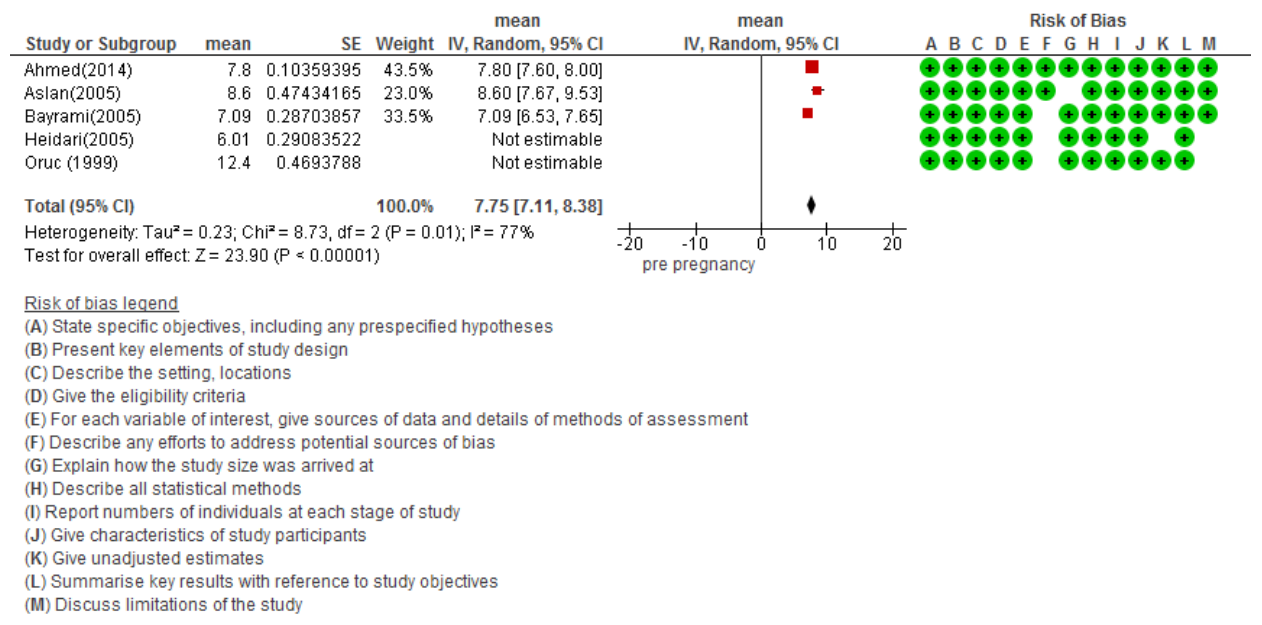

Figure 2. Vaginal Intercourse Pre-pregnancy.

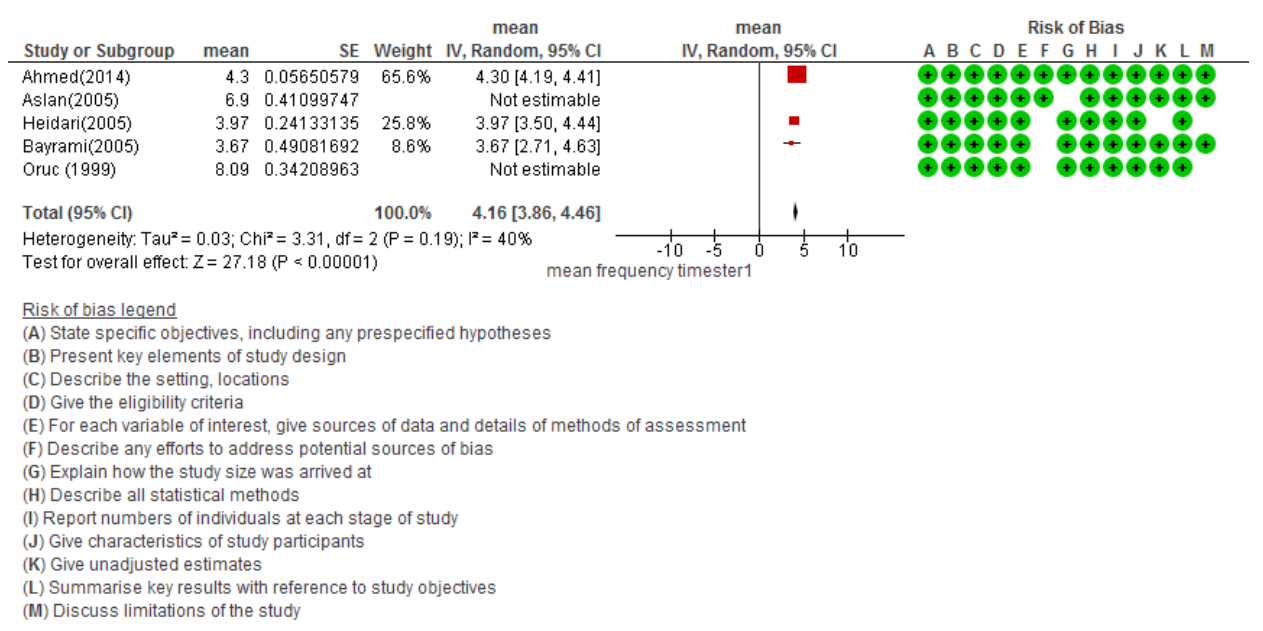

Figure 3. Vaginal Intercourse in the First Trimester. 


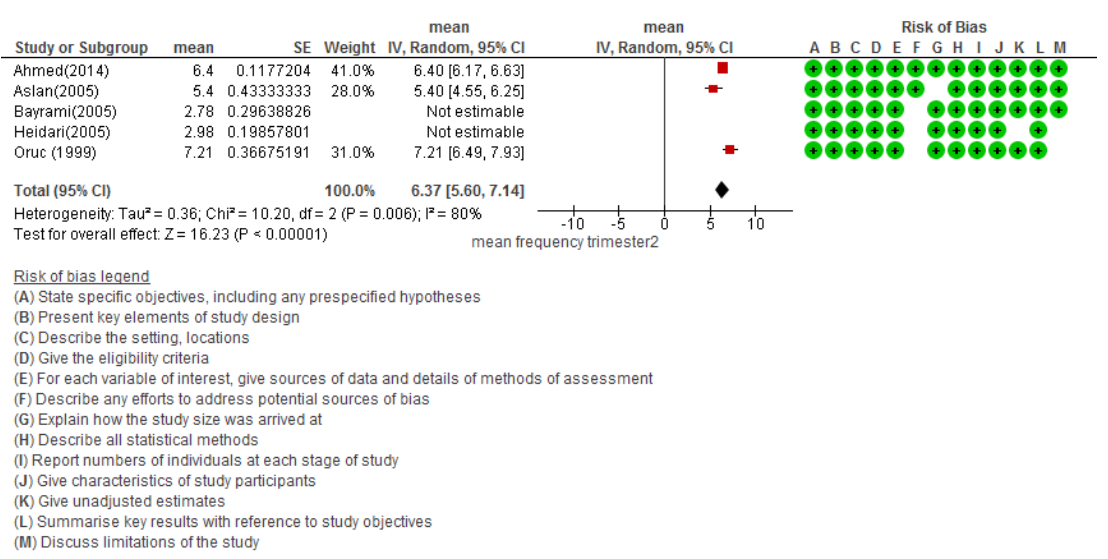

Figure 4. Vaginal Intercourse in the Second Trimester.

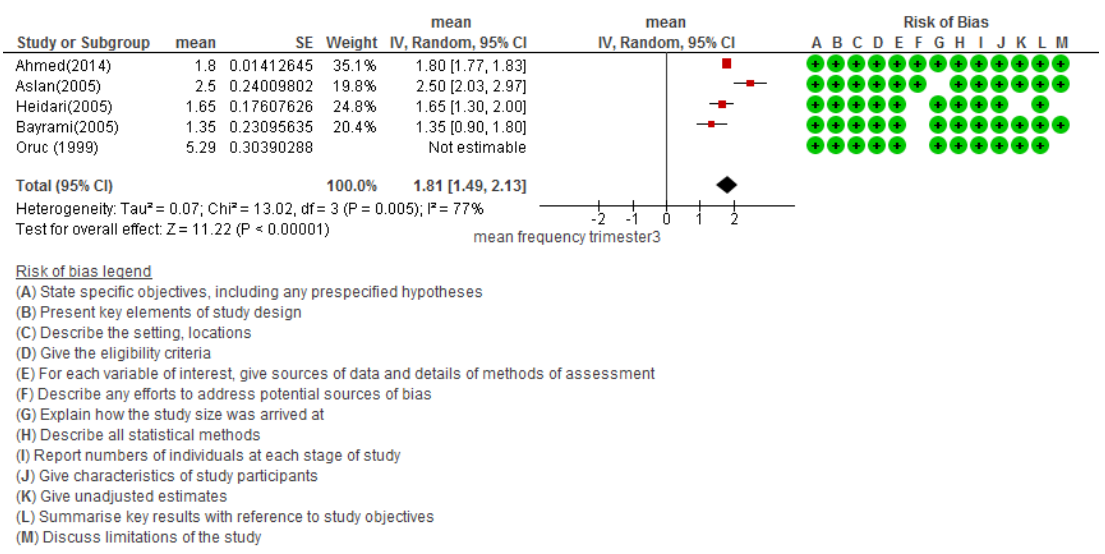

Figure 5. Vaginal Intercourse in the Third Trimester



Figure 6. Sexual Activity Changes During Pregnancy.

women reported a decline in their vaginal intercourse and only $1-19 \%$ of them highlighted an increase in vaginal intercourse frequency $(8,9,37,41)$. Therefore, generally, a decrease in the frequency of vaginal intercourse was expected. However, one prospective study including
70 American women found no significant changes in the frequency of vaginal intercourse (26). In this study, no report was provided regarding the mean of vaginal intercourse rather the prevalence of women having vaginal intercourse approximately 1-4 times monthly and those 
having more than 4 times vaginal intercourse monthly was pinpointed. Further, no significant changes were found in the first trimester compared to pre-pregnancy. However, the pattern of vaginal intercourse in women having intercourse once a month was considerably different from those of women having intercourse 4 times per month, that is, once a week and their classification may justify why this result is totally unexpected.

As regards the findings of the current meta-analysis, the mean of vaginal intercourse frequency decreased during the first trimester of pregnancy while it increased in the second trimester. However, a further decline was observed in the third trimester. In the following sections, the findings of the present review study are compared to those of other studies.

The results of the present study are in line with the findings obtained by the following studies:

Bartellas et al reported that $75 \%$ of the women had less vaginal intercourse in the second trimester in comparison to pre-pregnancy (41).

Furthermore, based on the studies conducted by Orji et al (8) and Bogren (37) no changes occurred in the frequency of vaginal intercourse in more than $60 \%$ of the women in the second trimester. However, only in 25\% (8) and $37 \%$ of them (37), a decrease was observed in vaginal intercourse frequency. Therefore, a slight decline of vaginal intercourse frequency was expected in the second trimester compared to pre-pregnancy.

Similarly, Pauleta et al indicated that $31 \%$ and $23 \%$ of the women reported a decrease in frequency of vaginal intercourse in the first and second trimester, respectively (9). Conversely, however, the results of some studies do not match the findings of the current study.

A meta-analysis study conducted by von Sydow demonstrated that sexual intercourse frequency did not significantly change during the first and the second trimesters, however, it decreased significantly during the third trimester (19). Moreover, Hart et al, Adeyemi et al, and Erenel et al found a gradual decline in vaginal intercourse in their studies $(34,36,50)$.

Additionally, Rahimi et al and Gökyildiz and Beji reported that the frequency of intercourse decreased progressively during the pregnancy compared to the prepregnancy period $(12,32)$.

Esmer et al indicated that vaginal intercourse frequency reduced significantly in the second and third trimesters of pregnancy compared to the first trimester (2).

Accordingly, a question arises that whether the frequency of vaginal intercourse in the second trimester was negligible or not compared to the first trimester.

To answer this question, this meta-analysis was conducted focusing on the studies reporting the mean frequency of vaginal intercourse. The results revealed that it reduced during the first trimester of pregnancy whereas it enhanced in the second trimester. And finally, it decreased in the third trimester for the second time. Probably, if gestational age was near to the beginning of the second trimester, which the effects of abdomen enlargement were not very obvious, it would be different from the end of this trimester.

Most authors observed a marked reduction in vaginal intercourse during the final trimester. Esmer et al reported a significant difference in the prevalence of sexual avoidance in the first and second trimesters compared to the third trimester. In other words, it was significantly higher than that of the previous trimesters.

A decline in sexual activity is possibly due to the factors causing a fear. Women may experience painful intercourse, spotting following intercourse with deep penetration, uterine contractions due to the orgasm, fear of rupture of membrane (ROM), infections, and early delivery. In addition, abdomen distension is another factor for sexual limitation such that some positions impede the intercourse. These discrepancies in results reported by the researchers might be due to the data collection time. They should have clearly reported that in which gestational weeks, namely, particularly in the beginning or at the end of the 2 last trimester, the data were collected. If the sampling was conducted at the beginning of the third trimester, perhaps the mean frequency of vaginal intercourse could have been similar to that of the second trimester.

Ganem suggested that sexuality during pregnancy should be divided into four phases: from conception to 12 weeks, 12 to 32 weeks, 32 to 36 weeks, and the last month of pregnancy (36 weeks and more). It seems that using these phases can be useful to properly report the results (6).

This meta-analysis study included numerous studies that did not report standard deviation (SD). Thus, the authors could not enter them into the current metaanalysis. This might have had some effects on the results of our study.

\section{Conclusions}

Generally speaking, the results of this systematic metaanalysis review indicated that vaginal intercourse frequency changed throughout the pregnancy and showed some slight changes in the second trimester while it considerably decreased in the first and third trimesters, especially in the final weeks of pregnancy. Due to the significant reduction in vaginal intercourse during the pregnancy, particularly in the third trimester, couples may experience other types of sexual activity, which is not necessarily a reason for the reduced quality of sexual life. Therefore, this issue is subject to further investigation.

The findings are extremely important for clinicians and health care providers. Clients should receive adequate information about the permissibility of sexual intercourse in normal pregnancies. In the cases of vaginal intercourse prohibition, alternative approaches should be recommended.

\section{Conflict of Interests}

Authors declare that they have no conflict of interests. 


\section{Ethical Issues}

The current review study was approved by the Ethical Committee of Shahroud University of Medical Sciences (Ethics No. IR.SHMU.REC.1395.97).

\section{Financial Support}

This review study is part of a Ph.D. thesis (code: 96147) supported by Shahroud University of Medical Sciences.

\section{Acknowledgments}

We are thankful for the financial support provided for this thesis.

\section{References}

1. Pastore L, Owens A, Raymond C. Postpartum sexuality concerns among first-time parents from one U.S. academic hospital. J Sex Med. 2007;4(1):115-123. doi:10.1111/j.17436109.2006.00379.x

2. Corbacioglu Esmer A, Akca A, Akbayir O, Goksedef BP, Bakir VL. Female sexual function and associated factors during pregnancy. J Obstet Gynaecol Res. 2013;39(6):11651172. doi:10.1111/jog. 12048

3. Escudero-Rivas R, Carretero P, Cano A, Cruz M, Florido J. Modifications of sexual activity during uncomplicated pregnancy: A prospective investigation of Spanish women. Health. 2013;5(8):1289-1294. doi:10.4236/ health.2013.58175

4. Erol B, Sanli O, Korkmaz D, Seyhan A, Akman T, Kadioglu A. A cross-sectional study of female sexual function and dysfunction during pregnancy. J Sex Med. 2007;4(5):13811387. doi:10.1111/j.1743-6109.2007.00559.x

5. Ahmed MR, Madny EH, Sayed Ahmed WA. Prevalence of female sexual dysfunction during pregnancy among Egyptian women. J Obstet Gynaecol Res. 2014;40(4):10231029. doi:10.1111/jog. 12313

6. Polomeno V. Sex and Pregnancy: A Perinatal Educator's Guide. J Perinat Educ. 2000;9(4):15-27. doi:10.1624/105812400x87879

7. Jawed-Wessel S, Sevick E. The Impact of Pregnancy and Childbirth on Sexual Behaviors: A Systematic Review. J Sex Res. 2017;54(4-5):411-423. doi:10.1080/00224499.2016.127 4715

8. Orji EO, Ogunlola IO, Fasubaa OB. Sexuality among pregnant women in South West Nigeria. J Obstet Gynaecol. 2002;22(2):166-168. doi:10.1080/01443610120113319

9. Pauleta JR, Pereira NM, Graca LM. Sexuality during pregnancy. J Sex Med. 2010;7(1 Pt 1):136-142. doi:10.1111/ j.1743-6109.2009.01538.x

10. Smith A, Lyons A, Ferris J, et al. Sexual and relationship satisfaction among heterosexual men and women: the importance of desired frequency of sex. J Sex Marital Ther. 2011;37(2):104-115. doi:10.1080/0092623x.2011.560531

11. Aslan G, Aslan D, Kizilyar A, Ispahi C, Esen A. A prospective analysis of sexual functions during pregnancy. Int J Impot Res. 2005;17(2):154-157. doi:10.1038/sj.ijir.3901288

12. Gokyildiz S, Beji NK. The effects of pregnancy on sexual life. J Sex Marital Ther. 2005;31(3):201-215. doi:10.1080/00926230590513410

13. Uwapusitanon W, Choobun T. Sexuality and sexual activity in pregnancy. J Med Assoc Thai. 2004;87 Suppl 3:S45-49.
14. Karabulutlu O, Yilmaz D. Effects of Pregnancy on Female Sexuality. Int J Recent Sci Res. 2018;9(2(A)):23744-23752. doi: 10.24327/ijrsr.2018.0902.1530.

15. Johnson CE. Sexual health during pregnancy and the postpartum. J Sex Med. 2011;8(5):1267-1284; quiz 12851266. doi:10.1111/j.1743-6109.2011.02223.x

16. Serati M, Salvatore S, Siesto G, et al. Female sexual function during pregnancy and after childbirth. J Sex Med. 2010;7(8):2782-2790. doi:10.1111/j.17436109.2010.01893.x

17. Murtagh J. Female sexual function, dysfunction, and pregnancy: implications for practice. J Midwifery Womens Health. 2010;55(5):438-446. doi:10.1016/j. jmwh.2009.12.006

18. Alsibiani SA. Effects of pregnancy on sexual function. Findings from a survey of Saudi women. Saudi Med J. 2014;35(5):482-487.

19. von Sydow K. Sexuality during pregnancy and after childbirth: a metacontent analysis of 59 studies. J Psychosom Res. 1999;47(1):27-49. doi:10.1016/s0022-3999(98)00106-8

20. Dwyer JM. High-risk sexual behaviours and genital infections during pregnancy. Int Nurs Rev. 2001;48(4):233240. doi:10.1046/j.1466-7657.2001.00083.x

21. Tabande A, Behnampour N, Joudi Mashahd M, Ghafari Cherati S, Alaee E. Sexual Satisfaction of Women with Gestational Diabetes. J Mazandaran Univ Med Sci. 2016;26(140):202-205.

22. Stammler-Safar M, Ott J, Weber S, Krampl E. Sexual behaviour of women with twin pregnancies. Twin Res Hum Genet. 2010;13(4):383-388. doi:10.1375/twin.13.4.383

23. Kisa S, Zeyneloglu S, Yilmaz D, Guner T. Quality of sexual life and its effect on marital adjustment of Turkish women in pregnancy. J Sex Marital Ther. 2014;40(4):309-322. doi:1 0.1080/0092623x.2012.751071

24. Corbacioglu A, Bakir VL, Akbayir O, Cilesiz Goksedef BP, Akca A. The role of pregnancy awareness on female sexual function in early gestation. J Sex Med. 2012;9(7):1897-1903. doi:10.1111/j.1743-6109.2012.02740.x

25. Torkestani F, Hadavand SH, Khodashenase Z, et al. Frequency and Perception of Sexual Activity during Pregnancy in Iranian Couples. Int J Fertil Steril. 2012;6(2):107-110.

26. Pauls RN, Occhino JA, Dryfhout VL. Effects of pregnancy on female sexual function and body image: a prospective study. J Sex Med. 2008;5(8):1915-1922. doi:10.1111/j.17436109.2008.00884.x

27. Fox NS, Gelber SE, Chasen ST. Physical and sexual activity during pregnancy and near delivery. J Womens Health (Larchmt). 2008;17(9):1431-1435. doi:10.1089/ jwh.2007.0730

28. Senkumwong N, Chaovisitsaree S, Rugpao S, Chandrawongse W, Yanunto $\mathrm{S}$. The changes of sexuality in Thai women during pregnancy. J Med Assoc Thai. 2006;89 Suppl 4:S124-129.

29. Eryilmaz G, Ege E, Zincir H. Factors affecting sexual life during pregnancy in eastern Turkey. Gynecol Obstet Invest. 2004;57(2):103-108. doi:10.1159/000075582

30. Haines CJ, Shan YO, Kuen CL, Leung DH, Chung TK, Chin R. Sexual behavior in pregnancy among Hong Kong Chinese women. J Psychosom Res. 1996;40(3):299-304.

31. Naim M, Bhutto E. Sexuality during pregnancy in Pakistani 
women. J Pak Med Assoc. 2000;50(1):38-44.

32. Rahimi S, Seyyed Rasooly E. Sexual behavior during pregnancy: A descriptive study of pregnant women in Tabriz, Iran. Payesh. 2004;3(4):291-299.

33. Adinma JI. Sexuality in Nigerian pregnant women: perceptions and practice. Aust N Z J Obstet Gynaecol. 1995;35(3):290-293. doi:10.1111/j.1479-828X.1995. tb01984.x

34. Hart J, Cohen E, Gingold A, Homburg R. Sexual Behavior in Pregnancy: A Study of 219 Women. J Sex Educ Ther. 1991;17(2):86-90. doi:10.1080/01614576.1991.11074009

35. Galazka I, Drosdzol-Cop A, Naworska B, Czajkowska M, Skrzypulec-Plinta V. Changes in the sexual function during pregnancy. J Sex Med. 2015;12(2):445-454. doi:10.1111/ jsm. 12747

36. Adeyemi AB, Fatusi AO, Makinde ON, Omojuwa I, Asa S, Onwudiegwu U. Changes in sexual practices and responses among ante-natal clinic attendees in a Nigerian teaching hospital. J Obstet Gynaecol. 2005;25(8):796-802. doi:10.1080/01443610500328306

37. Bogren LY. Changes in sexuality in women and men during pregnancy. Arch Sex Behav. 1991;20(1):35-45. doi:10.1007/ bf01543006

38. Trutnovsky G, Haas J, Lang U, Petru E. Women's perception of sexuality during pregnancy and after birth. Aust N Z J Obstet Gynaecol. 2006;46(4):282-287. doi:10.1111/j.1479828X.2006.00592.x

39. Nakic Rados S, Soljacic Vranes H, Sunjic M. Sexuality during pregnancy: what is important for sexual satisfaction in expectant fathers? J Sex Marital Ther. 2015;41(3):282293. doi:10.1080/0092623x.2014.889054

40. Pasha H, Haj Ahmadi M. Evaluation of Sexual behaviors in pregnant women and some related factors, Babol, Iran 2004. Med J Hormozgan Univ. 2007;10(4):343-8.

41. Bartellas E, Crane JM, Daley M, Bennett KA, Hutchens D. Sexuality and sexual activity in pregnancy. BJOG. 2000;107(8):964-968. doi:10.1111/j.1471-0528.2000. tb10397.x

42. DeJudicibus MA, McCabe MP. Psychological factors and the sexuality of pregnant and postpartum women. J Sex Res. 2002;39(2):94-103. doi:10.1080/00224490209552128

43. al Bustan MA, el Tomi NF, Faiwalla MF, Manav V. Maternal sexuality during pregnancy and after childbirth in Muslim Kuwaiti women. Arch Sex Behav. 1995;24(2):207-215.

44. Chang SR, Chen KH, Lin HH, Yu HJ. Comparison of overall sexual function, sexual intercourse/activity, sexual satisfaction, and sexual desire during the three trimesters of pregnancy and assessment of their determinants. J Sex Med. 2011;8(10):2859-2867. doi:10.1111/j.17436109.2011.02420.x

45. Sayle AE, Savitz DA, Williams JF. Accuracy of reporting of sexual activity during late pregnancy. Paediatr Perinat Epidemiol. 2003;17(2):143-147. doi:10.1046/j.13653016.2003.00476.x

46. Vandenbroucke JP, von Elm E, Altman DG, et al. Strengthening the Reporting of Observational Studies in Epidemiology (STROBE): explanation and elaboration. Int J Surg. 2014;12(12):1500-1524. doi:10.1016/j. ijsu.2014.07.014

47. Higgins JP, Thompson SG, Deeks JJ, Altman DG. Measuring inconsistency in meta-analyses. BMJ. 2003;327(7414):557560. doi:10.1136/bmj.327.7414.557

48. Hyde JS, DeLamater JD, Plant EA, Byrd JM. Sexuality during pregnancy and the year postpartum. J Sex Res. 1996;33(2):143-151. doi:10.1080/00224499609551826

49. Liberati A, Altman DG, Tetzlaff J, et al. The PRISMA statement for reporting systematic reviews and meta-analyses of studies that evaluate health care interventions: explanation and elaboration. PLoS Med. 2009;6(7):e1000100. doi:10.1371/journal.pmed.1000100

50. Erenel AS, Eroglu K, Vural G, Dilbaz B. A pilot study: In what ways do women in Turkey experience a change in their sexuality during pregnancy? Sex Disabil. 2011;29(3):207216. doi:10.1007/s11195-011-9200-1

(C) 2019 The Author (s); This is an open-access article distributed under the terms of the Creative Commons Attribution License (http://creativecommons.org/licenses/by/4.0), which permits unrestricted use, distribution, and reproduction in any medium, provided the original work is properly cited. 